Int.J. Hum. Soc. Dev. Res.

ISSN (P):2521-1439; ISSN (E):2523-4331

Volume 3, № 1, 2019. 102-121

DOI: $10.30546 / 2523-4331.2019 .3 .1 .102$

\title{
IMPLEMENTING SDGs: ACTORS AND POLICIES NEEDED AND BARRIERS OVERCOME
}

\author{
Aytan TAGHIYEVA \\ Researcher, Azerbaijan
}

\section{Kamala HASHIMOVA}

Researcher, Azerbaijan

\section{(C) The Author(s) 2019}

\begin{abstract}
The study presents barriers on the implementation of Sustainable Development Goals (SDGs). SDGs should be implemented at four levels including national, regional, global and thematic. Many countries experience difficulties while implementing SDGs at the national level. The paper explores Azerbaijan as a case study and explains five challenges faced on SDG implementation. First of all, government needs National Action Plan for the adaptation of SDGs to the national context and prioritization of the goals according to their importance at the national level. Secondly, special coordinating agencies, funding units, regional and other ad-hoc committees and expert panel are absent in the newly established system. Regarding the civil society participation, despite the Post-2015 consultations, main constraint is the low level of public awareness which leads to the underrepresentation of the vulnerable members of the society that are children, youth and etc. Apart from this, there are also some management constraints for implementing the SDGs at the governmental level which includes budget allocation, special procedures, and political \& legislative framework. After all, Azerbaijan needs strong statistical capacity, which will result in data revolution for SDGs implementation. The study also investigates actors and policies needed in order to overcome barriers on the SDG implementation. Thus, based on the successful experiences of three countries such as Finland, Turkey and Georgia, special model was created for a better mechanism on the SDG implementation for Azerbaijan where all the gaps were addressed.
\end{abstract}

C2019.All rights reserved

ARTICLE HISTORY

Received: $15 / 11 / 2018$

Accepted: 10/03/2019

Published online: 01/04/2019

\section{KEYWORDS}

Sustainable Development Goals (SDGs), SDG Implementation Azerbaijan, Action Plan and Coordination Mechanism, Society Participation, Management Challenges, Statistical Capacity 


\section{Introduction}

Sustainable Development Goals (SDGs) has already started in June 2012 with The Rio+20 conference (the United Nations conference on Sustainable Development) in Rio de Janeiro (SDGF), which marked the end of Millennium Development Goals (MDGs) (Harvard International Review, 2015). As a consequence, in September 2015 the UN General Assembly approved a new development agenda containing seventeen SDGs (Figure1) proposed by the UN General Assembly Open Working Group (OWG) for the next 15 years (UNICEF, 2015a). New 2030 agenda has been designed for sustainable transformation of the world by including the most vulnerable people, ending poverty and hunger, providing full gender equality, upgrading health services and ensuring quality education for every child.

Figure 1. Sustainable Development Goals

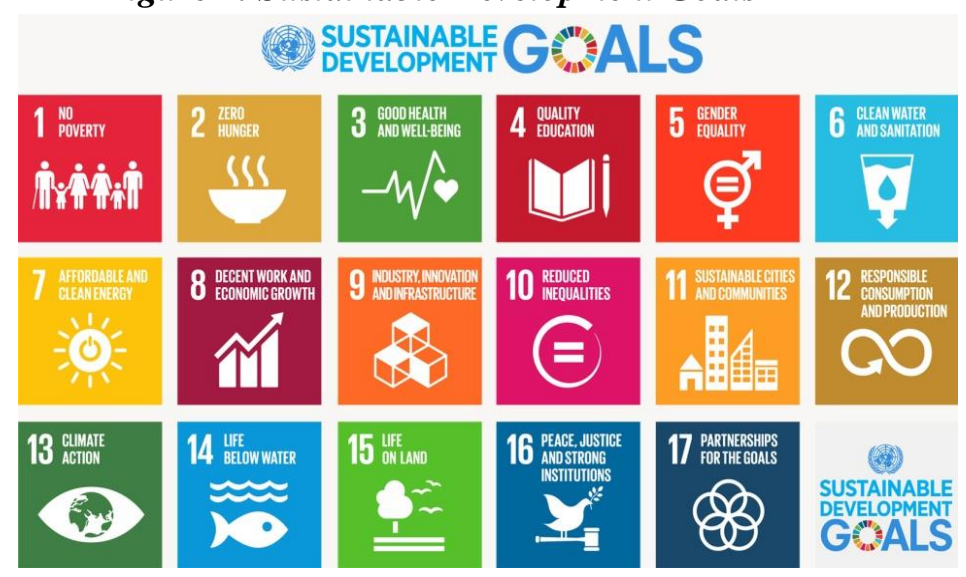

In order to achieve these global goals a number of stakeholders such as governments, civil society, the private sector, the UN system, individuals were involved in drafting the new sustainable development agenda (UNICEF, 2013). The new project has quickly attained momentum because of the increasing importance of sustainable development for the whole world. Sustainable development is the universal framework which consists of social, environmental, economic and governmental challenges. According to the generally recognized definition, "Sustainable development is development that meets the needs of the present without compromising the ability of future generations to meet their own needs" (UNICEF, 2013).

Sustainable development requires intra-dimensional and inter-dimensional progress: inclusive economic development, inclusive social development, environmental sustainability; and base for all of these, the rule of law. It is should be noted that to get better results in all the dimensions following the principles such as human rights, equity and sustainability is essential (UNICEF, 2013). It was recognized that, first of all, the sustainable development needs data revolution for monitoring the progress, 
strengthening accountability and making urgent interventions to advance the development at all levels and dimensions (UN, 2015). In this regard, the major challenges for governments are the poor data quality including shortage of timely data and unavailability of disaggregated data, ineffective coordination and management mechanisms, as well as weak society participation in the process.

The purpose of this research is to explore the effective implementation framework of Sustainable Development Goals (SDGs) at the national level and come up with the recommendations for improving the current SDG mechanism. Thus, Azerbaijan is analyzed as a case study and recommendations based on the expertise of other states such as Finland, Turkey and Georgia provided. The study is highly important in terms of the findings and recommendations which may contribute to effective SDG Implementation Mechanism in Azerbaijan through created special model.

\section{Methodology}

This is an analytical policy study examining the implementation structure of the SDGs at the national level based on the Azerbaijani case. In order to explore these mechanisms, primary (expert commentary and data table) and secondary sources (both qualitative and quantitative data) are used and analyzed comparatively. Qualitative data includes a number of articles, news, reports, reviews, expert views, documents, issue briefs and guidelines of UN specialized agencies, while quantitative data relies on the Global SDG Indicators Database, statistical information provided by UN agencies and relevant state offices. Particularly, information by the State Statistical Committee of the Republic of Azerbaijan which is responsible for preparing SDG indicators is very supportive for the study. However, there can be possible limitations stemming from the fact that it will require several years to prepare and issue data on the SDGs. Finally, TOWS analysis of the other states such as Finland, Turkey and Georgia on SDG practice are done and compared, where possible recommendations are proposed for Azerbaijan on the SDG implementation mechanism.

\section{Results and discussions \\ SDG Implementation}

Implementation of the SDGs must be carried out at multiple levels - national, regional, global and thematic (UNICEF, 2015). The improvement of monitor-measurereport system will appear on the four levels simultaneously. Globally, the process has already began, however in another three scales actions are needed to be undertaken for the advancement and harmonization of implementation activities (Pinter,2014). In general, global monitoring will provide worldwide cooperation on the SDGs and it will also display which countries have progress and which ones lag behind in this process. In turn, that will contribute to the reciprocal learning from experiences (SDSN, 2015). For 
that purpose, firstly, indicators needed for the global reporting were adopted by the Economic and Social Council and the General Assembly. Regional monitoring will encourage the shared responsibility on problems in the regions and if possible, also should be based on regional mechanisms. In terms of thematic reporting, countries should support the implementation of SDGs through the thematic communities (in the auspice of international organizations) by providing reports on various themes such as education, health, etc. (SDSN, 2015).

There is a guidance to help the governments in the national level implementation of the SDGs and the 2030 Agenda for Sustainable Development. According to this guidance, generally, implementation should be at three stages: plan, do and check (figure2) (Mauring, 2015).

Figure 2. The 2030 Agenda Mainstreaming Guidance Areas for implementing the 2030 Agenda for Sustainable Development and Adapting SDGs to National Contexts

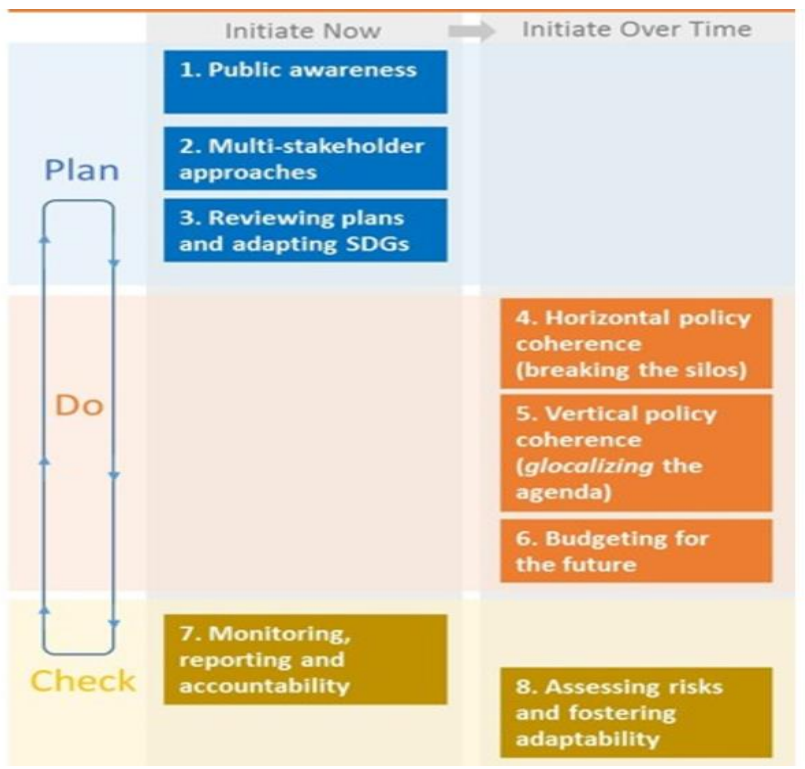

Although the implementation of complex SDG monitoring will take certain years, decisions should be made soon. Here the main focus must be on the national monitoring as OWC underlined (Mothe et al. 2015). Therefore, National Monitoring is the most significant part of the monitoring process which based on indicators determined in the national level. This monitoring must rely on the priorities of the nations, meaning that countries can identify indicators, methods of data collection and their disaggregation that will respond to their national needs. In this stage, each state should decide whether they can use unofficial data such as NGO surveys, information from private satellites which will make their monitoring rich. For the purpose of providing comparability there should be harmonization between the global and national 
indicators, however matched global indicators are very costly to the National Statistic Offices and also to the stakeholders of the states. Thus, Complementary National Indicators is another option for the addressing country-specific issues (SDSN, 2015).

Modernized state statistical capacities (especially in developing countries) are the cornerstone for collection of multidimensional high quality and high frequency data. Accordingly, with the aim of following the progress on SDGs high quality, high frequency, timely and reliable data will be revolutionary.

Openness, exchange of metadata and micro data for disaggregation are the fundamental elements of data revolution. Systematic production and usage of administrative data will be necessary to enhance government performance. Furthermore, household surveys and censuses will be complementary in this process. National statistical offices will lead the process of preparation of national indicators by recommendations of all stakeholders (UN team, civil society, ministries, planners, decision-makers, etc). Thus, data mapping and classification of national SDG indicators will guarantee systematic implementation of SDGs (UNDG, 2017).

The initial steps in implementation and reporting progress on the SDGs are Voluntary National Reviews (VNRs). This is the foundation for the reports that given by the states and is very important because of shared experiences that will facilitate measuring progress towards reaching the SDGs.

\section{Figure 3. The building blocks of National Review process}

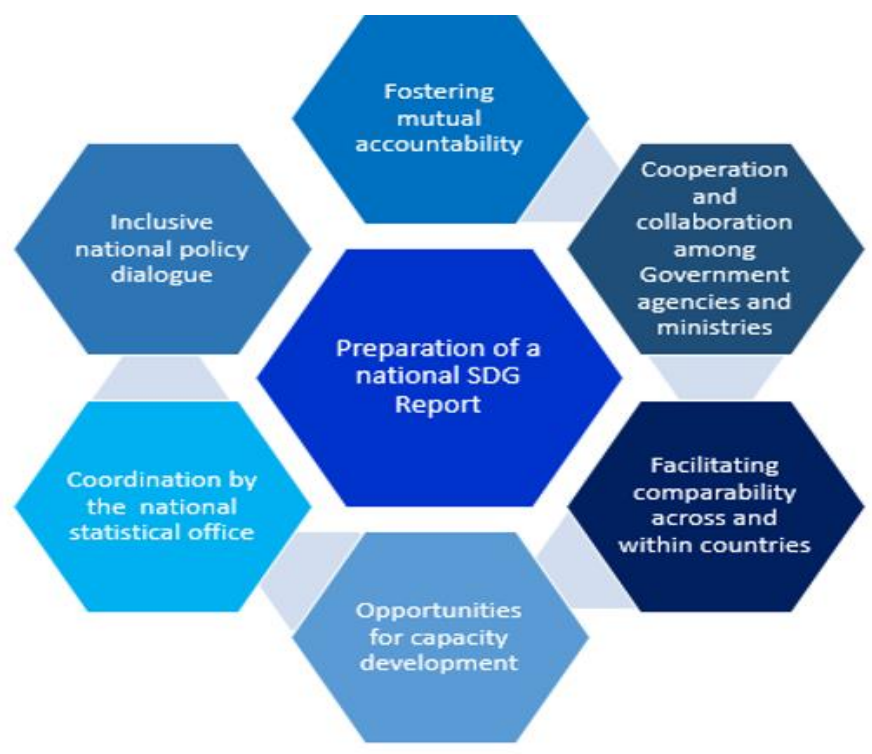

Importantly, National Report is the main component of national review system (figure3). Apart from tracking progress on the SDG indicators it determines 
implementation gaps (data and strategies), policy challenges, explains factors behind trends and present suggestions for challenges (UNDG, 2017).

\section{Azerbaijani Case}

Innovative mechanism is a prerequisite for the successful implementation of the SDGs in Azerbaijan. Thus, at the national level the presence of better mechanism is very essential for the country in the implementation of the SDGs, which is the starting point on the progress towards the SDGs. In this regard, the practices of other countries on the effective SDGs implementation process will contribute to addressing the existing deficiencies in the mechanism for implementing the SDGs in Azerbaijan. Also, the usage of international methods and comments of international organizations will make implementation process better in Azerbaijan. When the gaps in the Azerbaijani SDG mechanism are identified, there will be recommendations based on the UN system reports and experiences of successful countries such as Finland, Turkey and Georgia the ways that they are solving the challenges such as data availability, administrational issues, public awareness etc. for the implementation of the SDGs.

\section{Barriers Overcome}

\section{Action Plan still in Progress}

While SDGs are universal, some targets will be much more significant than others according to the specific country conditions. In case of Azerbaijan, improving social protection with particular attention to vulnerable people, preventing harmful effects of energy industry for environmental protection and achieving "green economy" are priority aspects of global goals (UNECE, 2015). It is quite common to adapt global targets and indicators to the national context. Azerbaijani government is going to harmonize global goals via "contextualization" accompanying the national state programs and plans. For the purpose of achieving sustainable development the amount of state budget allocated to essential areas such as environmental protection, healthcare and education will be increased. The implementation process will be controlled by the Ministry of Economy and other state institutions. In this light, government is going to arrange bilateral and multilateral meetings, seminars, roundtable discussions, etc. to accelerate decision-making on the implementation of global agenda and to produce better recommendations (UNECE, 2015). However, it is clear that without support of UN structures (policy dialogue, advice, and expertise) to achieve such ambitious goals will be very difficult for the states. Therefore, UN system will strengthen its structures across the regions and improve inter-agency cooperation for achieving universal agenda post-2015. The Azerbaijani government needs collaboration with UN regional structures particularly in tackling with "serious regional environmental problems; assessment of and recovery from the damage to environment, cultural monuments and social 
infrastructure caused by conflicts; protection of rights of refugees and internally displaced people; protection of historical architectural monuments and cultural heritage" (UNECE, 2015). In this process, UNDP will be major agency for capacity building in the country and will contribute to the activities of government bodies dealing with the Post-2015 agenda.

\section{Recommendations:}

In order to accelerate the preparation phase, Azerbaijani government needs new projects for the assessment of the SDG implementation process, exclusively gap analysis such as the Avain2030 Project of Finland and Research team of Turkey in the Post-2015 Data Test.

The Avain2030 Project (figure4) was initiated for helping the Finnish government to identify the defects and strengths of the country in the implementation of the SDGs. The project provided recommendations for the Action Plan there (Lyytimäki et. al 2016).

Figure 4. The phases of the Avain2030 project

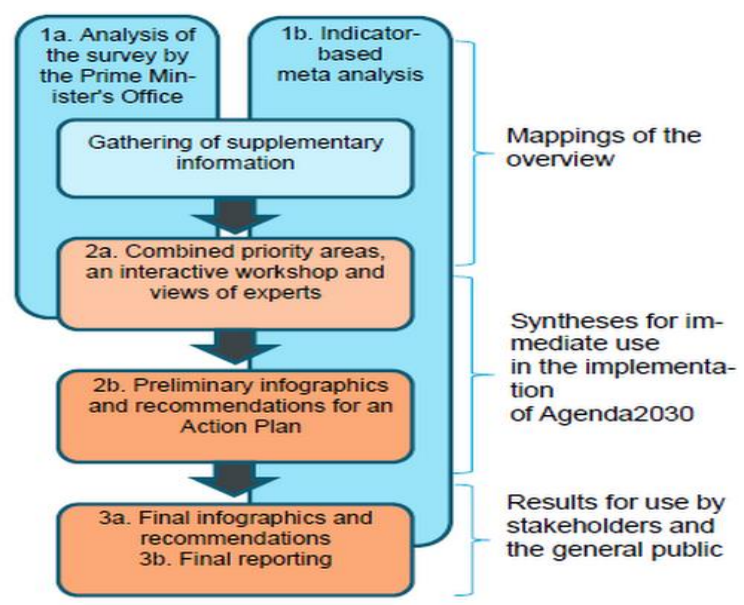

In the case of Azerbaijan, via this kind of project the potential steps might be as followings:

- $\quad$ Assessment of the current policy measures by different government agencies based on the surveys that will be obtained. After that, with the help of indicator based Meta-analysis the rank of Azerbaijan will be identified in comparison with the international indicators on the SDGs. This phase will lead to the collection of the supplementary information for the SDGs. 
- $\quad$ For the next stage, the most essential SDG areas will be chosen on the basis of workshops (via Real time electronic Screen.io program) and expert views. Info graphics will be created for the visualization of the SDG implementation.

- Lastly, stakeholder involvement will be increased for the final recommendations.

Team of researchers in Turkey that was responsible for the particular SDGs (Post-2015 Data Test) in the preparation stage might be beneficial experience for Azerbaijan (Post-2015 Data Test, 2015). By the establishment of this group of experienced researchers, Azerbaijani government will intensify the preparation process. Accordingly, they can help to the SSC in the comparison of the global data with the national one as they have deep information about data search \& usage.

\section{Newly established Coordination Mechanism}

Institutional level - Main functions of the SDG Department in the SSC includes: analysis, selection and identification of the SDG indicators; scientific-practical and statistical investigations for measurement structure on SDGs; and development (collecting and processing) of the official statistical data for sustainable development at the national level (Safarov, 2017).

High political level - National Coordinating Council for Sustainable Development (NCCSD) takes responsibility for coordination among government bodies in the context of SDGs, defining the national priorities along with SDGs, preparing annual SDG report, cooperating with international experts, creating working groups in different fields and matching the state programs to the framework of SDGs (Safarov, 2017). Creating this Council is essential for cross-sectoral integration of SDGs in Azerbaijan context. The council also supports three sectoral working groups such as economic growth and decent work, social issues and environmental issues established by Secretariat (Safarov, 2017). While these working groups get involved in the mapping process of SDGs at the national level by the guidance of the Ministry of Economy, line government agencies (central \& local executive authorities and legal entities) are accountable for delivering administrative data to the SSC on SDG indicators and informing the NCCSD on the required actions (Figure5) (Safarov, 2016a). 
Figure 5. High Political level on the SDGs in Azerbaijan

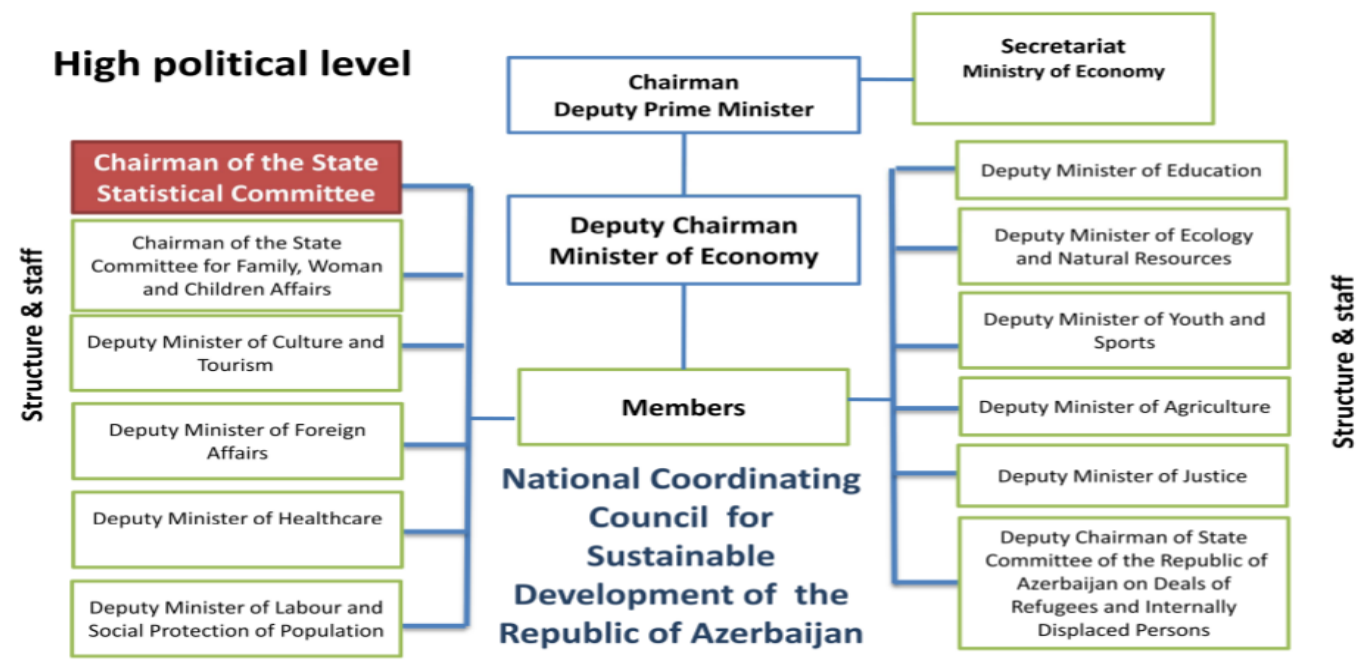

After all, there is also a project undertaken by Secretariat for the SDGs alignment, prioritization, and integration process which is in progress. This project aims to define the list of priority SDGs to be integrated into national planning frameworks; facilitate activities of the NCCSD Secretariat; prepare an Action Plan on incorporating SDGs; arrange a high level workshop to confirm the results of incorporating and adapting of SDGs to the national context; and support in preparing the national SDG report (Safarov, 2016b). Relevant Ministries and the representatives of the NCCSD are obliged to provide accountability framework on monitoring the progress on State Programmes coordinated to SDGs (Safarov, 2016b). Azerbaijan's first voluntary national report was presented to the High Level Political Forum in July 2017, where steps taken by Azerbaijan on the implementation of the SGDs were emphasized (Azernews, 2017).

\section{Recommendations}

Azerbaijan established network of government agencies for the implementation of the SDGs, however there is a need to increase the number of line government bodies for this purpose:

Significantly, guidance and support of the Coordination Network will be very necessary in the implementation and also creating National Indictor Network will be very supportive to the monitoring and evaluation of the sustainable development as it was in Finland (VNR Finland, 2016). Based on the Finnish experience, organizing the Expert Panel on SDGs assessment will intensify the process and involvement of the Parliament for monitoring and implementation of 
the SDGs will make Azerbaijani government more responsible towards the agenda.

Formation of the separate departments for the SDG implementation such as in Georgia will enhance the situation on the SDGs in Azerbaijan. Notably, department same as the Donor Coordination Unit will increase interaction between the national government and international agencies, which will ease the implementation under the support of international community(UNDG, 2016).

\begin{abstract}
$>$ Establishment of Ad-hoc Committees and Regional Development Agencies which contributed to the implementation process in Turkey (SDG Report of Turkey, 2016), might be also better practice for Azerbaijan. Such bodies will include various expert views which will lead to multi-dialogue actions and increase SDG policy in the regions, respectively.
\end{abstract}

\title{
3. Week Society Participation
}

In order to intensify inter-linkages among SDG contributing bodies, it is crucial to create universal agenda and give opportunity to society for participation in agenda setting. UN agencies led national consultations that continued four month in order to figure out suggestions of Azerbaijani people for sharing global vision. The consequences of "Post-2015 national consultations" are compatible with our society's priorities which are articulated in strategic plan of "Azerbaijan: Vision 2020" (National Report, 2013). Citizens' consultations were achieved by online ("The World We Want" web platform and UNICEF's Facebook page) and offline survey methodology ("My World Survey"). In 2013, the first round named "The Future We Want" was carried out and ten priorities (Table1) were identified to define future road map according to uncompleted missions of MDG. In comparison with the first round, the second round was consulted among youth named as "Dialogue with Civil Society and Other Actors: Youth." As a result, seven priority areas were identified in 2014 (Figure6), whereas measurements, methodology and questions were the same with the first round (National Consultations, 2014).

The first round mainly concentrated on vulnerable groups (youth, children, IDPs, women etc), while the second was about youth from different fields and groups. The second round attracted a total of 800 young people, while they were very active stakeholders accounting for 1300 people out of 2723 respondents in the first round. According to the results of My World Survey conducted in 2013 and 2014, voters identified three main priority areas firstly "getting a good education", secondly " achieving better working opportunities" and finally "benefiting from better healthcare", which helped to establish future concepts. Although the consultation attracted various 
stakeholders, these consultations cannot be considered as wide scope society participation. Particularly, underrepresentation of vulnerable groups such as women, child and youth in the policy processes is necessary issue to be addressed too. With regard to this challenge, the conference 'The role of civil society in achieving objective of sustainable development in Azerbaijan' was held on May1, 2017 in Baku (Report News Agency, 2017). Besides, Ruslan Ismayilzadeh, former Communication Officer at UNDP, also highlighted enhancing the participation of children and young decisionmakers through raising public awareness.

Figure 6. Priorities of the first and second round of Post-2015 National Consultations

\begin{tabular}{|c|c|}
\hline First Round & Second Round \\
\hline $\begin{array}{l}\text { 1.Economic } \\
\text { diversification and } \\
\text { inclusive growth }\end{array}$ & $\begin{array}{l}\text { 1.Development of a quality and inclusive } \\
\text { education system, and the prioritization of } \\
\text { vocational education }\end{array}$ \\
\hline $\begin{array}{l}\text { 2.Rural development } \\
\text { and quality infrastructure }\end{array}$ & $\begin{array}{l}\text { 2.Diversification of the economy, and } \\
\text { creation of employment opportunities; global } \\
\text { cooperation for youth development }\end{array}$ \\
\hline $\begin{array}{l}\text { 3.Enhanced quality and } \\
\text { access to healthcare }\end{array}$ & $\begin{array}{l}\text { 3.Empowerment of youth in decision- } \\
\text { making }\end{array}$ \\
\hline $\begin{array}{l}\text { 4.Improving } \\
\text { opportunities for youth }\end{array}$ & 4.Provisions for gender equality \\
\hline $\begin{array}{l}\text { 5.Gender equality and } \\
\text { women's empowerment }\end{array}$ & 5.Establishment of a better healthcare for all \\
\hline $\begin{array}{l}\text { 6.Promoting internally } \\
\text { displaced person's self- } \\
\text { reliance }\end{array}$ & 6.Development of rural areas and agriculture \\
\hline $\begin{array}{l}\text { 7.Good governance and } \\
\text { effective institutions }\end{array}$ & $\begin{array}{l}\text { 7.Environmental sustainability in the face of } \\
\text { climate change, and access to safe, drinkable } \\
\text { water }\end{array}$ \\
\hline \multicolumn{2}{|l|}{$\begin{array}{l}\text { 8.Ensuring food and } \\
\text { nutritional security }\end{array}$} \\
\hline \multicolumn{2}{|l|}{$\begin{array}{l}\text { 9.Environmental } \\
\text { sustainability }\end{array}$} \\
\hline $\begin{array}{l}\text { 10.Effective } \\
\text { management }\end{array}$ & \\
\hline
\end{tabular}




\section{Recommendations}

In order to increase the level of public participation in the SDG implementation process, policies and programs especially designed for society should be adopted:

$>\quad$ “Qualified people, Strong Society" in Turkey (SDG Report of Turkey, 2016) and Society's Commitment to Sustainable Development and its operational commitments in Finland (VNR Finland, 2016) can be the best guides for Azerbaijan which will include society, members of both public and private sectors in decision-making process. Azerbaijan can also use Turkey's method of increasing public awareness on SDGs via

media which will cause speedy expansion of knowledge on the issue (SDG Report of Turkey, 2016).

$>$ Initiating pilot project such as "Supporting the Implementation of Sustainable Development Goals (SDG) in Georgia" during one year will be excellent course of action for raising public awareness based on monthly activities (indicated through numbers below) in Azerbaijan (IDFI, 2017). The second section of this project is designed for conducting a comprehensive public awareness campaign on SDGs which can address weak society participation problem of Azerbaijan through the following actions.

Figure 7. Monthly activities of "Supporting the Implementation of Sustainable Development Goals (SDG) in Georgia” project ( $2^{\text {nd }}$ part)

\begin{tabular}{|l|c|}
\hline $\begin{array}{l}\text { Comprehensive Public Awareness Campaign on SDGs } \\
\text { /Activities }\end{array}$ & Month \\
\hline Preparing an outline for public discussions & 2,5 \\
\hline Conducting at least three public discussions on SDGs & $3,6,9$ \\
\hline Conducting an analytical paper contest on SDGs & $6,7,8$ \\
\hline $\begin{array}{l}\text { Conducting workshops about SDGs for representatives of public } \\
\text { institutions }\end{array}$ & $8,9,10$ \\
\hline Conducting lectures in three different regions & 4,7 \\
\hline Conducting workshops for representatives of CSOs & 10 \\
\hline $\begin{array}{l}\text { Conducting a workshop for representatives of private companies } \\
\text { and media }\end{array}$ & 11 \\
\hline Organizing media campaign about SDGs & $9,10,11$ \\
\hline Organizing an international forum about SDG Goal 16 & 9, \\
\hline
\end{tabular}


(IDFI, 2017)

\section{Management Challenges}

During the recent years, although development of the capacities is recorded, there are still existing number of challenges such as participation, accountability and transparency for the Azerbaijani Government in the implementation of the SDGs. As mentioned in the UNAPF document, primary gaps exist:

- In the policy and legislative framework of the country that will lead to the establishment of the adverse socio-cultural practices.

- In the public services sector low level of information sharing and poor management are the main problems, thereby there is a strong need for the intensified service delivery at the local extent.

- Procedural obstacles exist in the implementation of the SDGs that require an improved order for carrying out the programs, policies and laws.

- Allocation of the budget to the primary social services is also the main matter that needed to be strengthened.

\section{Recommendations}

For addressing allocation of the budget Azerbaijan can use Finnish budget planning method such as budget proposals by various institutions for achieving short and medium-term SDGs (VNR Finland, 2016). In addition, by mobilizing private sector resources in terms of including companies of Azerbaijan operating in the local and international arena for making investment can also solve management problem.

> Preparation of Short, Medium and Long-term programs for implementation should be very necessary step as it was in Turkey (SDG Report of Turkey, 2016). Particularly, Medium-term programs will help annual budget preparation on the basis of period plans for three years.

For solving obstacles in the policy and legislative structure, Azerbaijani government should join Open Government Partnership such as Georgia, which will contribute to open government and transparency (Parliament of Georgia, 2015). In turn, this will intensify the SDG implementation process at the Azerbaijani national level.

\section{Statistical Capacity}

Considering the methods of implementation, the role of science, technology and innovation; exchange of experiences; and mobilization and effective use of domestic resources should be emphasized. The major problems the SCC is facing are: methodology and techniques for developing SDG indicators; disaggregated data; 
monitoring and reporting the progress towards SDGs and capacity building for this process (Safarov, 2016b). In these terms, national capacity necessities include data processing, survey methodologies, planning, budgeting, IT software \& hardware (data communication network) and M\&E capacity that were reported by Arif Ibishov, deputy head of SDG department. As a consequence, strategic development targets for SSC are mainly about improving technical aspects and modern equipments; professionalism and know-how; electronic data exchange, coordination of metadata and use of administrative data; conduction and analysis of surveys; and integration of central, regional and local networks (Safarov, 2017). From this point of view, importance of science was also highlighted by the conference "The role of science and research in achieving the sustainable development goals in Azerbaijan".

National reports are fundamental for the follow-up process of SDGs. The content and structure of national reports which are government-led will be based on data availability and other limitations. It is planned to engage relevant ministries and state bodies, nongovernmental organizations, regional and international organizations in preparing the progress reports on the SDGs. Furthermore, the best international methods, practices and active public engagement will be utilized in this process (UNECE, 2015). At the end, the national progress report should be published in several foreign languages for submitting resident UN agencies (UNECE, 2015). For the purpose of answering the call of "data revolution" which deems necessary high-quality data for better monitoring, government takes measures to improve statistical capacity, adapt the national statistics system to international standards, and guarantee progress of a single information system of the state statistics organs and e-statistics (UNECE, 2015). It is planned to add data on sustainable development for the corresponding national statistical indicators annually and carry out surveys in different social sectors for further information. Respectively, international expertise will be employed for conducting surveys on unemployment, poverty, and environmental protection. According to the collected data, the causes of drawbacks or lags will be identified and possible interventions will be taken. Additionally, the recommendations and suggestions of the international and regional organizations will be taken into regard to assure successful SDG implementation (UNECE, 2015).

At the national level, there are six data sources for SDGs: Current observation of businesses, Economic Census, Agricultural Census, Population Census, Statistical surveys on social demographic issues and Administrative records. According to the analysis of the SSC of Azerbaijan Republic, only 30\% of existing data at the national level corresponds to SDG indicators, while 33\% of the data doesn't fit to the post-2015 agenda. However, it is considered that $37 \%$ of the data can be improved as a potential source (Safarov, 2016b). In that sense, there are 70 indicators belonging to 14 SDG goals at the national level, while the number of indicators can be increased up to 85 including 17 goals. 


\section{Recommendations}

$>$ First of all, enhancing science \& technology, promoting innovation, providing exchange of experiences, exclusively via cooperation with international experts, efficient mobilization of the country's resources is very important step for the development of the statistical capacity.

$>$ For the gap analysis Azerbaijan can use Finland model, exactly Preliminary Sustainable Development Goal (PSDG) Index which will figure out in which goals Azerbaijan needs actions to be taken in order to improve the situation related to the SDGs. In addition, international indicator comparison such as OECD Index Comparison will help comparison of Azerbaijan with other countries in the initial stage of SDGs (VNR Finland, 2016). One and four year cycle plans for the follow-up\& review of the SDG implementation will be very crucial for Azerbaijan, as it will ensure self-assessment of Azerbaijani government and will increase its accountability on the SDGs. Creating agency such as the National Audit Office VTV in Finland that will publish statement on the performance of government on SDGs will increase the responsibility even more (Government Report Finland 2017).

$>$ Surveys conducted in Finland and Turkey based on international standards can be also very important example for Azerbaijan in monitoring and reporting (in terms of indicators).

$>$ In case of Turkey, comprehensive patterns in tackling data problems for Azerbaijan might be: Official Statistical Program for finding indicator gaps (evaluation, dissemination and compilation of data); Indices as the

very effective means of measuring progress for informing decisionmakers and public; BIST Sustainability Index to measure involvement of Private sector in data gathering and stimulate this sector for voluntary monitoring and reporting (SDG Report of Turkey, 2016).

> Establishing and launching an Electronic Monitoring System for SDGs which is a part of Georgian Pilot Project (figure8) may also be very practical and necessary for Azerbaijan (IDFI, 2017). For that purpose, required steps are: 
Figure 8.Monthly activities of "Supporting the Implementation of Sustainable Development Goals (SDG) in Georgia" project (1 ${ }^{\text {st }}$ part)

\begin{tabular}{|c|c|}
\hline Electronic Monitoring System for SDGs/Activities & Months \\
\hline $\begin{array}{l}\text { Mapping public institutions responsible for the implementation of } \\
\text { SDG Goal 16, targets and other goals for future expansion of the } \\
\text { monitoring system }\end{array}$ & 1 \\
\hline $\begin{array}{l}\text { Preparing a needs assessment document that will include input } \\
\text { from Ministry of Economy and other public institutions }\end{array}$ & 2 \\
\hline $\begin{array}{l}\text { Selecting of an international expert for an elaboration of the } \\
\text { monitoring methodology }\end{array}$ & 1 \\
\hline Preparing a monitoring methodology for SDG G16 & $1,2,3$ \\
\hline Preparing Terms of Reference (TOR) for the electronic system & 2,3 \\
\hline Creating a Business Model of the System & 2,3 \\
\hline Preparing graphic design of the system & 3 \\
\hline Development of the electronic system is finished & $2,3,4$ \\
\hline Training of Ministry of Economy staff is conducted & 4 \\
\hline Training of the beneficiary agency staff is conducted & 4 \\
\hline Preparing a manual on administration and use of the EMS & 5 \\
\hline $\begin{array}{l}\text { Preparing a pilot monitoring report for SDG Goal } 16 \text { using the } \\
\text { data aggregated through the EMS }\end{array}$ & 5 \\
\hline
\end{tabular}

(IDFI, 2017) 


\section{An effective mechanism on SDGs implementation for Azerbaijan}

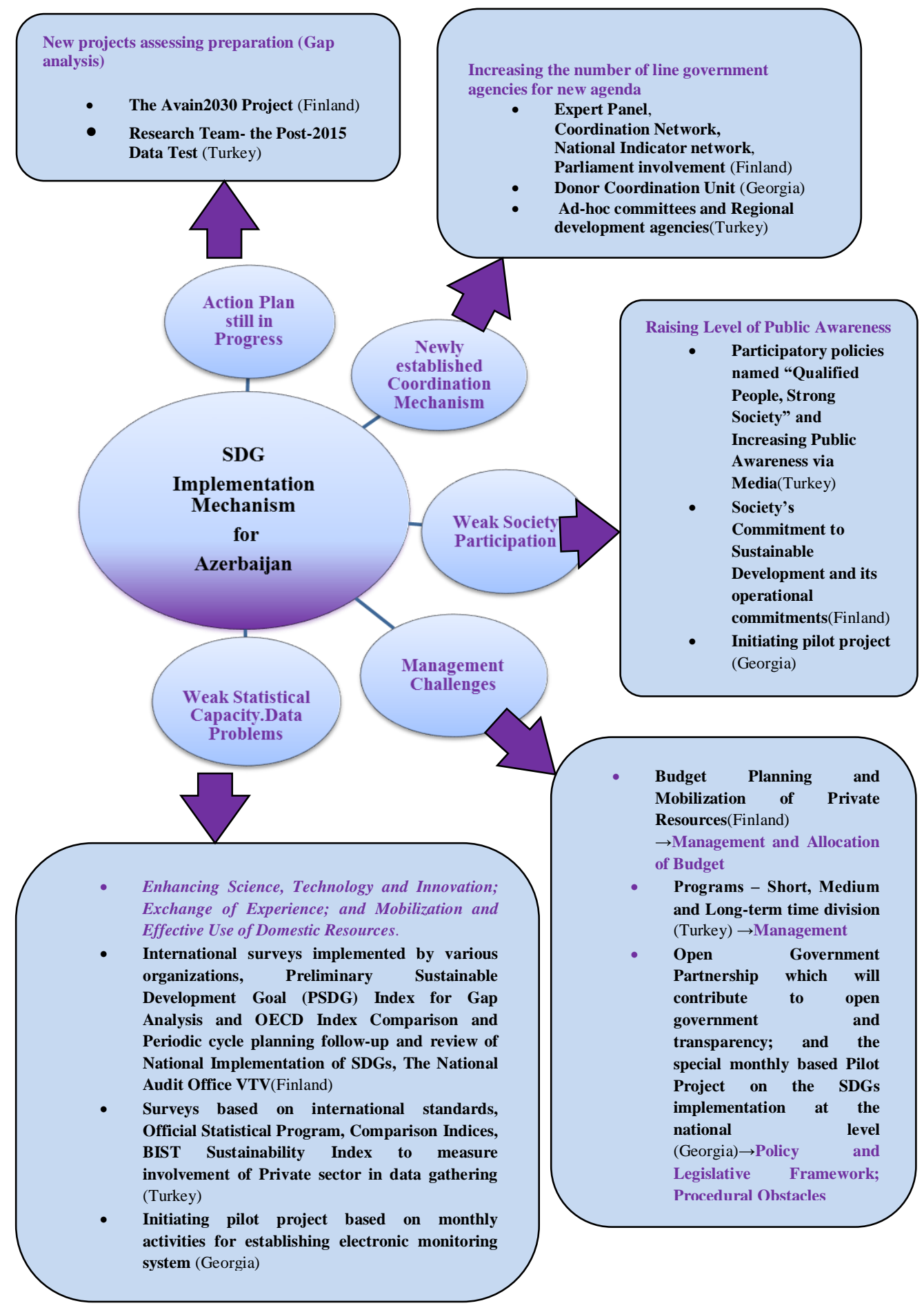

Int.J. Hum. Soc. Dev. Res. 
As a conclusion, it should be noted that many countries experience problems while implementing SDGs. Data and management problems, statistical capacity, weak society participation and policy challenges are the main issues. Thus, SDG implementation should be realized at the four levels including national, regional, global and thematic for overcoming existing barriers.

As a developing country, Azerbaijan also has problems on SDG implementation. However, it should be emphasized that Azerbaijani government is working on the development strategies and plans for the SDGs in order to intensify sustainable development at the national level. Accordingly, cooperation with the local and international agencies is the main priority of government for this objective. Nevertheless, Azerbaijan has restraints on the measuring progress towards the SDGs since the country has insufficient capacity for the preparation and implementation phases. In this light, progress will be made and completed if Azerbaijani government is able to detect present deficiencies in the existing SDG system. By addressing these drawbacks, the country will be able to achieve systematic, inclusive and innovative mechanism for measuring progress towards the SDGs. For this purpose, proposed recommendations based on the practices of successful countries as mentioned above can be supportive in the formation of new effective mechanism for implementation of SDGs in Azerbaijan.

\section{Disclosure statement}

No potential conflict of interest was reported by the authors.

\section{Contact Information}

E-mail: kamala@yahoo.com 


\section{References and notes:}

Azernews (2017, July).Azerbaijan presents voluntary national review at High-Level Political Forum on Sustainable Development. Retrieved from

https://www.azernews.az/nation/116473.html

Government Report Finland (2017) implementation of the 2030 Agenda for Sustainable Development. Sustainable Development in Finland - Long-term, Coherent and Inclusive Action. Prime Minister's Office Publications.

Harvard International Review (2015).Investing in All Children: Towards Equitable, Inclusive, and Sustainable Development.

IDFI (2017).Supporting the Implementation of Sustainable Development Goals in Georgia.Institute for Development of Freedom of Information.

Lyytimäki,J.,Lähteenoja,S., Sokero,M.,Korhonen,S., Furman, E. (2016). Agenda 2030 in Finland: Key questions and indicators of sustainable development. Prime Minister's Office.

Mauring, F. (2015). The 2030 Agenda for Sustainable Development \&The UN approach to implementation. Abu Dhabi.

Mothe,E., Espey, J. and Schmidt-Traub, G. (2015). Measuring Progress on the SDGs: Multilevel Reporting.GSDR 2015 Brief.

National Final Report of Azerbaijan on Post-2015 Development Agenda Consultations (2013). "The Future We Want". The UN and Azerbaijan.

National Final Report of Azerbaijan on Post-2015 Development Agenda Consultations (2014). "Dialogue with Civil Society and Other Actors: Youth". UNDP, UNFPA, Ministry of Youth and Sport of the Republic of Azerbaijan, National Assembly of Youth Organizations of the Republic of Azerbaijan.

Parliament of Georgia (2015). The Parliament of Georgia endorsed the OGP Joint Declaration on "Open Government for Implementation of the 2030 Agenda for Sustainable Development"Retrieved from http://www.parliament.ge/en/gia-da-gamchvirvalemmartvelobis-mudmivmoqmedi-sabcho/axali-ambebi/saqartvelos-parlamenti-ogpis-deklaracias-gia-mmartveloba-mdgradi-ganvitarebis-dgis-wesrigis-ganxorci

Pinter, L. (2014).Monitoring and Reporting on Sustainable Development Goals: Cross scale linkages. Sharing Tools in Planning for Sustainable Development.

Post-2015 Data Test (2015).Country Level Experiences.Measuring Sustainable Development to 2030: A view from Turkey. Istanbul, Turkey.

Report News Agency (2017, May). Baku hosts conference 'The role of civil society in achieving objective of sustainable development in Azerbaijan'. Retrieved from https://report.az/en/domestic-politics/baku-hosts-conference-the-role-of-civilsociety-in-achieving-objective-of-sustainable-development-i/

Report on Turkey's Initial Step towards the Implementation of the 2030 Agenda for Sustainable Development (2016). SDG Turkey.Ministry of Development. Turkey.

Safarov.R (2016a). Arrangement of statistical data providing for reaching SDGs. Department of Sustainable Development Statistics, the SSC

Safarov.R (2016b). The role of the SSC in the implementation of SDGs in Azerbaijan

Safarov.R (2017) Priorities and coordination of capacity building in Azerbaijan. Department of Sustainable Development Statistics, the SSC

SDSN (2015).Indicators and a Monitoring Framework for the Sustainable Development Goals.Launching a Data Revolution for the SDGs.

Sustainable Development Goals Fund (SDGF).From MDGs to SDGs. Retrieved from http://www.sdgfund.org/mdgs-sdgs

UN (2016). First Voluntary National Review on Implementation of the Sustainable Development Goals, Georgia .Sustainable Development Knowledge Platform.The United Nations 
UN (2015).The Millennium Development Goals Report

UNAPF (2015). The United Nation - Azerbaijan Partnership Framework 2016-2020.

UNDG (2017). Guidelines to support country reporting on the Sustainable Development Goals.

UNECE (2015). Planning, implementation, follow-up and review of the Sustainable Development Goals. Regional survey by UNECE and the Regional UN Development Group for Europe and Central Asia.

UNICEF (2015a).A Post-2015 World Fit for Children. A review of the Open Working Group Report on Sustainable Development Goals from a Child Rights Perspective

UNICEF (2015b). Progress for Children Beyond averages: learning from the MDGs.

UNICEF (2013).A Post-2015 World Fit for Children. Sustainable Development Starts and Ends with Safe, Healthy and Well-Educated Children.

VNR Finland (2016).National report on the implementation of the 2030 Agenda for Sustainable Development. Prime Minister's Office Publications.

\section{Interview List}

1. Arif Ibishov - Deputy Head of Department of Sustainable Development Statistics (SSC Azerbaijan)

2. Ruslan Ismayilzada - Former Communications Officer at UNDP Azerbaijan

3. Tamerlan Rajabov -Child Rights Systems Monitoring Specialist at the UNICEF Azerbaijan 